\title{
Polyisoprene-nanostructured carbon composite (PNCC) organic solvent vapour sensitivity and repeatability
}

Gita Sakale, Maris Knite, Valdis Teteris, Juris Zavickis

Riga Technical University, Institute of Technical Physics

Environment protection is one of the most discussed topics today. Accordingly there is an increase in research and production of sensormaterials, which could detect leakages, monitor air quality and also could be used in industry for process control. Sensormaterial described above need to be at least sensitive to organic solvent vapour exposure limits determined by NIOSHA or OSHA. In the same time sensormaterial have to maintain response repeatability.

Our scientific group have produced PNCC with 4 mass parts of carbon black and tested it to toluene vapour concentration $754 \mathrm{mg} / \mathrm{m}^{3}$ (toluene TWA level). The composite electric resistance increased immediately with exposure to vapour. As reported previously [1] the composite electric resistance increase is due to tunneling current existence in thin layers of matrix between carbon black nanoparticles aggregates.

Composite samples have been prepared by solution mixing of polyisoprene and carbon black particles, which were prior to dispersed into chloroform by sonification. After that a definite number of mixed solution layers (6, 8 or 10) were coated onto substrate (epoxy resin) with embedded brass wires.

In this paper we will describe how variation of the composite carbon black content (4, 5 and 6 mass parts) near the percolation threshold influence organic solvent vapour sensitivity and repeatability.

[1] M. Knite, K. Ozols, G. Sakale, V. Teteris. Polyisoprene and high structure carbon nanoparticle composite for sensing organic solvent vapours. Sensors and Actuators B 126 (2007) 209-213. 


\section{Polyisoprene-nanostructured carbon composite (PNCC) organic solvent vapour sensitivity and repeatability}

\section{$\sin \mathrm{RS}$}

Spring meeting, 7-11 June, Strasbourg, France

\section{Introduction}

Environment protection is one of the most discussed topics today. Accordingly there is an increase in research and production of sensormaterials, which could detect leakages, monitor air quality and also could be used in industry for process control.

Elastomer chemiresistors can be defined as conductive polymer composites that absorb chemical species and swell, increasing resistance as a physical response to the presence of chemical species [1]. An elastomer chemiresitor anvantage is that the composite sensitivity and selectivity can be varied very widely due to large polymer material diversity and structure change possibilities with a target to detect particular analyte. Chemiresistors electric resistance increases immediately with exposure to vapour. As reported previously [2] the composite electric resistance increase causes the changes of tunneling currents in thin layers of matrix between carbon black nanoparticle aggregates.

Here polyisoprene-nanostructured carbon composite preparation methods significance is evaluated and PNCC organic solvent vapour sensitivity, response stability is presented.

\section{Carbon black percolation in polyisoprene}

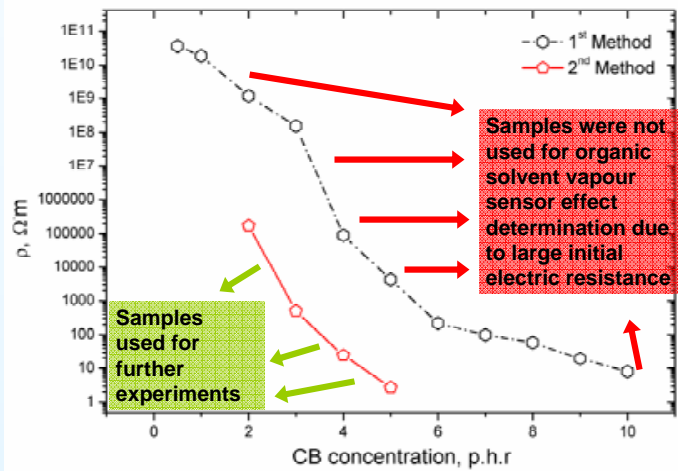

Fig.1. Percolation curves for PNCC prepared by $1^{\text {st }}$ and $2^{\text {nd }}$ method

PNCC sample design

Gita Sakale, Maris Knite, Valdis Teteris, Juris Zavickis

Institute of Technical Physics, Riga Technical University, Latvia corresponding author e-mail: gitasakale@inbox.Iv

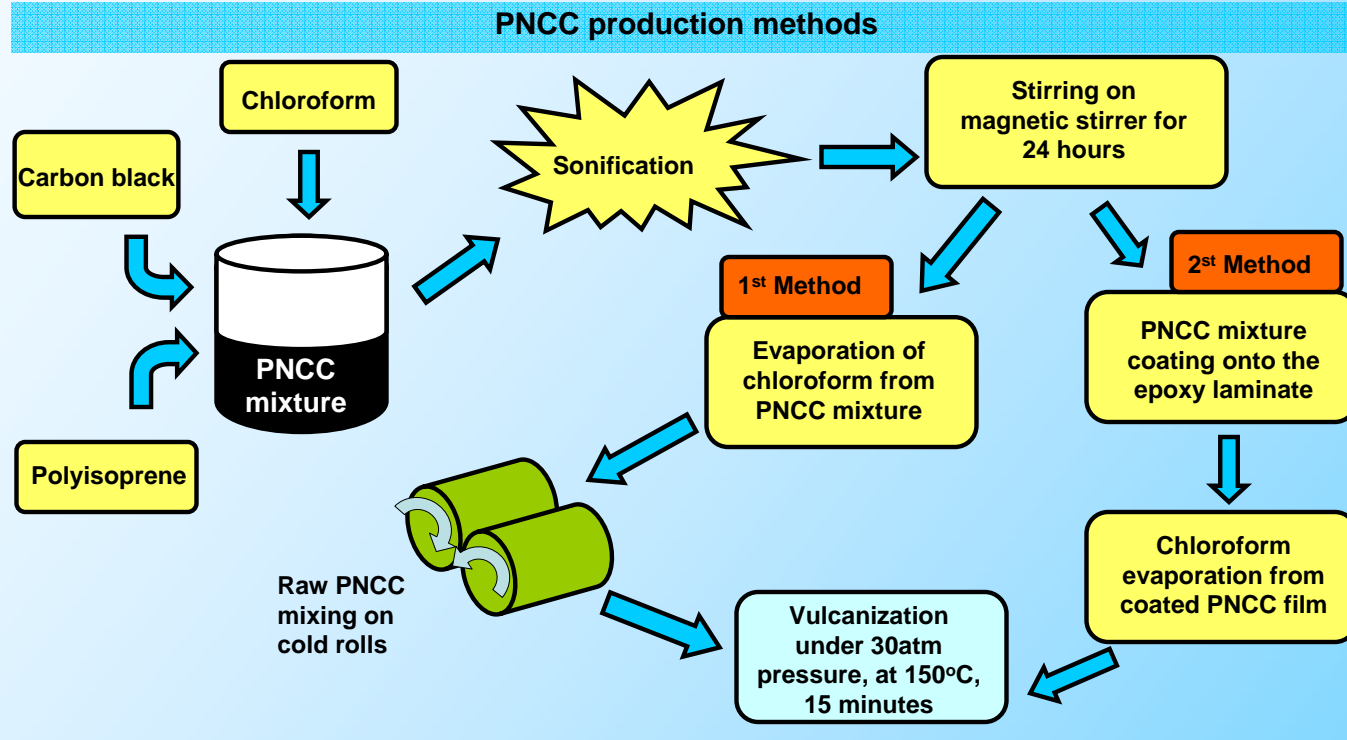

Measurement results

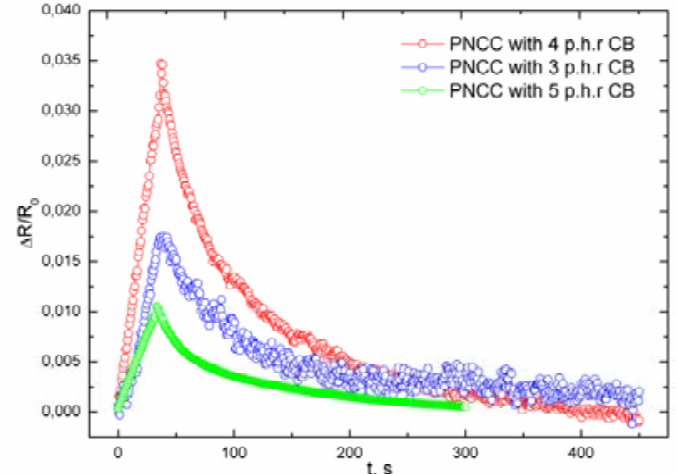

Fig.4. Toluene vapour sensoreffect for PNCC with different parts per hundred rubber (p.h.r) carbon black (CB). Toluene vapour concentration $2000 \mathrm{ppm}$. Samples were held in vapour for 30 s and then fallows electric resistance relaxation in the air. Thickness of samples $40 \mu \mathrm{m}$

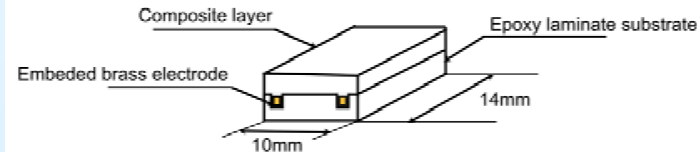

Fig.2. Schematic structure of PNCC sample.
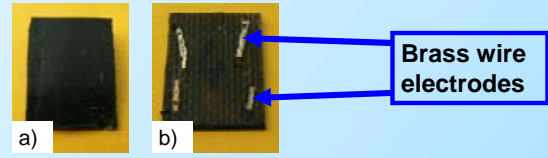

Fig.3. a) front of the PNCC sample. b) Reverse side of the PNCC sample.

\section{Conclusions}

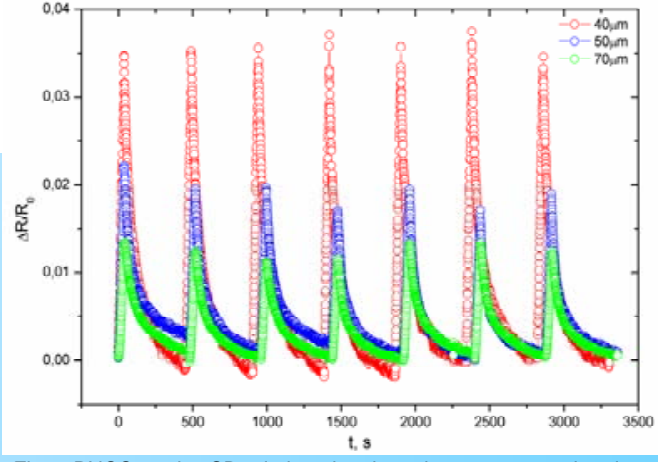

Fig.6. PNCC-4 p.h.r CB relative electric resistance versus time in toluene vapour (2000ppm) 30s and resistance relaxation in the air. Samples with thickness $40 \mu \mathrm{m}, 50 \mu \mathrm{m}$ and $70 \mu \mathrm{m}$ were used.

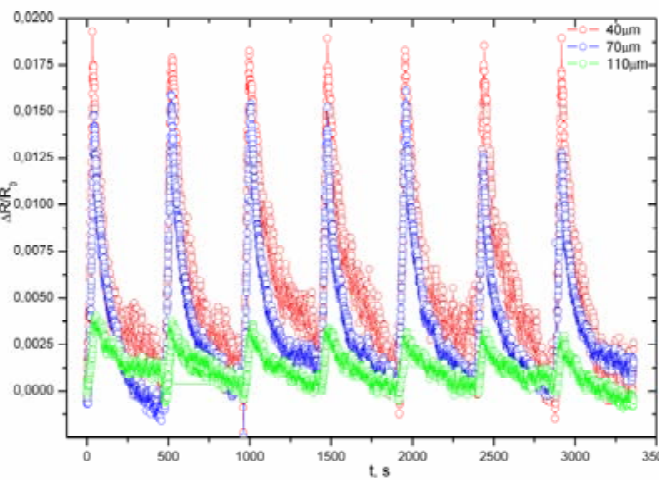

Fig.5. PNCC-3 p.h.r CB relative electric resistance versus time in toluene vapour (2000ppm) 30s and resistance relaxation in the air. Samples with thickness $40 \mu \mathrm{m}, 70 \mu \mathrm{m}$ and $110 \mu \mathrm{m}$ were used.

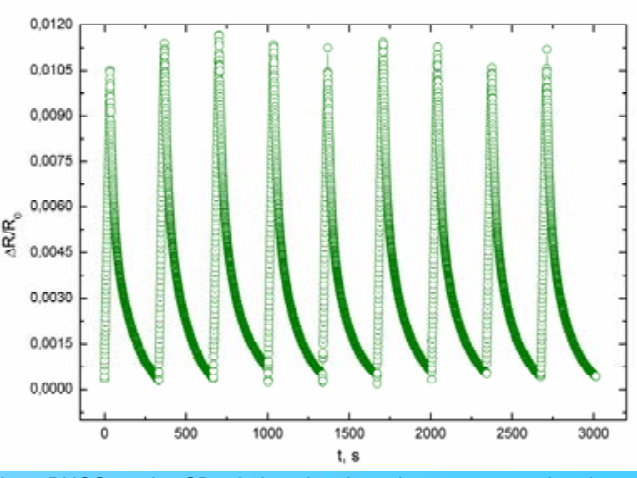

Fig.7. PNCC-5 p.h.r CB relative electric resistance versus time in toluene vapour (2000ppm) 30s and resistance relaxation in the air. Sample with thickness $40 \mu \mathrm{m}$ was used.

1. The selection of PNCC production method is essentially important. We have observed that percolation curve of PNCC shifts to lower specific electric resistance values if samples are made by $2^{\text {nd }}$ method. In the case of $1^{\text {st }}$ composite production method carbon black nanopraticles are more dispersed into polyisoprene matrix material due to additional raw PNCC mass mixing on cold rolls. As demonstrated by Zavickis et. al [3] dispersed carbon black nanoparticles re-agregate at the time of the composite vulcanization, which leads to electric conductivity arise into the composite. Therefore decrease in resistivity for samples made by $2^{\text {nd }}$ method can be explained by fewer destruction of carbon black nanoparticle aggregates at the time of mixing, which could lead to more conductive channel formation at the time of vulcaniation.

2. The best organic solvent vapour (osv) sensitivity is observed for PNCC with 4 p.h.r CB. But the worst osv sensitivity is obtained for PNCC with 5 p.h.r CB, meanwhile this composite shows the shortest electric resistance relaxation time.

3. PNCC osv sensitivity is strongly dependent of the composite sample thickness.

4. For all tested PNCC samples good electric resistance response stability is observed.

\section{References}

[1] Handbook of modern sensors, ed. by J.Fraden, Springer-Verlag, New York, USA (2004), p.505.

[2] M. Knite, K. Ozols, G. Sakale, V. Teteris. Polyisoprene and high structure carbon nanoparticle composite for sensing organic solvent vapours. Sensors and Actuators B 126 (2007) 209-213.

[3] J. Zavickis, M. Knite, K. Ozols, G. Malefan, Mg.sc.ing.Development of percolative electroconductive structure in piezoresistive polyisoprene-nanostructured carbon composite during vulcanization. In press: Materials Science and Engineering $\mathrm{C}$. 